\title{
COMPOSTOS DE LODO DE ESGOTO PARA A PRODUÇÃO \\ DE MUDAS DE Anadenanthera colubrina (Vell.) Brenan
}

\author{
Maurício Bergamini Scheer ${ }^{1}$, Charles Carneiro ${ }^{2}$, Otávio Augusto Bressan ${ }^{3}$, Kaline Gomes dos Santos ${ }^{4}$
}

(recebido: 16 de março de 2011; aceito: 29 de junho de 2012)

\begin{abstract}
RESUMO: A utilização de lodo de esgoto como insumo para culturas florestais é uma boa opção de destinação e aproveitamento desse resíduo sólido. Dessa forma, o objetivo deste trabalho foi avaliar o uso de compostos de lodo de esgoto aeróbio com podas de árvores trituradas e substrato comercial na produção de mudas de Anadenanthera colubrina (monjoleiro), com diferentes doses de fertilizante. Três doses de fertilizante de liberação lenta foram testadas $\left(0 ; 2,7\right.$ e $\left.4 \mathrm{~g} \cdot \mathrm{dm}^{-3}\right)$ em três tipos de substratos: comercial; composto à base de lodo na proporção 3:1 (v:v); e composto à base de lodo na proporção 2:1 (v:v). Foram mensuradas as seguintes características morfológicas: altura, diâmetro do coleto e massa seca da parte aérea (folhas e ramos). Considerando o crescimento das mudas sem adição de fertilizante, para todas as características morfológicas, os maiores valores foram obtidos com o uso de compostos à base de lodo como substrato em relação ao substrato comercial. Embora apresentados alguns valores superiores para doses mais altas, tanto para o substrato comercial quanto para os com lodo, a dose de $2,7 \mathrm{~g} \cdot \mathrm{dm}^{-3} \mathrm{de}$ fertilizante já mostrou-se adequada para a produção de mudas de monjoleiro, indicando quantidade suficiente de nutrientes para suprir as necessidades nutricionais para um bom crescimento das mudas, resultando em economia do insumo.
\end{abstract}

Palavras-chave: Biossólido, crescimento, fertilização.

\section{PRODUCTION OF Anadenanthera colubrina (Vell.) Brenan SEEDLINGS USING SUBSTRATES BASED ON COMPOSTED SEWAGE SLUDGE}

\begin{abstract}
The use of sewage sludge as raw material for forest growing is an alternative for the utilization and disposal of this solid waste. This work aimed at evaluating the use of a substrate based on composted sewage sludge and crushed pruning tree for the production of Anadenanthera colubrina seedlings (monjoleiro) using three different fertilization levels. Seedling growth was then compared to growth on a commercial substrate based on composted Pinus bark and vermiculite. Three levels of fertilization $(0 ; 2.7$ and $\left.4 \mathrm{~g} . \mathrm{dm}^{-3}\right)$ and three types of substrates were used: commercial substrate, and 3:1 (v:v) or 2:1 (v:v) composted substrate based on aerobic sewage sludge and crushed tree pruning. Seedling height, diameter and aerial dry mass (leaves and branches) were measured. Considering seedlings growth without fertilization, the greatest values for all morphological characteristics were obtained using composted substrate based on sewage sludge. Growth rates in all treatments using $2.7{\mathrm{~g} . d \mathrm{~m}^{-3}}^{-3}$ fertilizer, in many cases, can be considered sufficient, showing adequate amounts of nutrients to make up Anadenanthera colubrina seedling nutritional requirements and to promote adequate growth, with economy of the fertilizer.
\end{abstract}

Key words: Biosolids, fertilization, growth.

\section{INTRODUÇÃO}

A crescente coleta de efluentes urbanos e a necessidade de seu tratamento geram, diariamente, uma quantidade cada vez maior de lodo de esgoto. Sua disposição final tem se mostrado como um dos passivos urbanos mais relevantes da atualidade, causando a deterioração das condições ambientais com o aumento visível dos níveis de poluição(PEGORINI, 2002; ROCHA; SHIROTA, 1999).
O armazenamento de lodo de esgoto requer grandes áreas, o que além de envolver grandes riscos ambientais, torna-se dispendioso, fazendo-se necessário encontrar possibilidades viáveis para o seu uso. Como o lodo contém grande quantidade de matéria orgânica e nutrientes, uma das alternativas viáveis para a disposição desse resíduo é o seu uso como componente de substratos destinados a produção de mudas (ALTAFIN et al., 2004; FAUSTINO et al., 2005; GUEDES; POGGIANI, 2003; MORAIS et al., 1997;

\footnotetext{
${ }^{1}$ Engenheiro Florestal, Pesquisador Doutor em Engenharia Florestal - Companhia de Saneamento do Paraná/SANEPAR - Assessoria de Pesquisa e Desenvolvimento/APD - Rua Engenheiros Rebouças, 1376 - 80215-900 - Curitiba, PR, Brasil - mauriciobs@sanepar.com.br ${ }^{2}$ Engenheiro Agronômo, Pesquisador Doutor em Geologia Ambiental - Companhia de Saneamento do Paraná/SANEPAR - Assessoria de Pesquisa e Desenvolvimento/APD - Rua Engenheiros Rebouças, 1376 - 80215-900 - Curitiba, PR, Brasil - charlesc@sanepar.com.br ${ }^{3}$ Engenheiro Florestal - Universidade Federal do Paraná - Av. Pref. Lothário Meissner, 900 - Campus III - $80210-170$ - Curitiba, PR oabressan@gmail.com

${ }^{4}$ Engenheira Florestal - Universidade Federal do Paraná - Av. Pref. Lothário Meissner, 900 - Campus III - 80210-170 - Curitiba, PR kalinegs@hotmail.com
} 
SCHEER et al., 2010, 2011), tendo em vista a economia de fertilizantes que esse material proporciona para diversas culturas (MORAIS et al., 1997; NASCIMENTO et al., 2004; ROCHA et al., 2004; SILVAet al., 2002), além dos benefícios ambientais (GUERRINI; TRIGUEIRO, 2004).

Anadenanthera colubrina (Vell.) Brenan, conhecida como monjoleiro ou angico, é uma espécie secundária inicial (FERRETTI et al., 1995), formando, às vezes, capões puros em vegetação secundária (CARVALHO, 1994). Pertencente à família Fabaceae, é tolerante ao frio e apresenta crescimento de moderado a rápido e suas sementes possuem alto poder germinativo (CARVALHO, 1994). O mesmo autor ressalta que esta espécie possui características que a tornam promissora para reflorestamentos e uso energético, além de produzir abundante goma-resina, sendo considerada sucessora da goma-arábica.

Neste trabalho, objetivou-se: (1) avaliar o crescimento do Monjoleiro - Anadenanthera colubrina, em substratos à base de lodo de esgoto aeróbio compostado com podas de árvores trituradas, com diferentes níveis de fertilizante; e (2) comparar o desempenho em relação às mudas produzidas em substrato comercial à base de casca de Pinus compostada e vermiculita, amplamente utilizado em viveiros florestais.

\section{MATERIAL E MÉTODOS}

A condução do experimento ocorreu no município de Araucária, Paraná, no Viveiro Florestal do Passaúna, pertencente à Companhia de Saneamento do Paraná SANEPAR. O viveiro situa-se nas coordenadas $25^{\circ} 32^{\prime} 03^{\prime \prime} \mathrm{S}$ e 49 $23^{\prime} 15^{\prime \prime}$ O e possui altitude de $900 \mathrm{~m}$. Segundo a classificação de Köppen, o clima da região é Cfb (clima subtropical com verões frescos), apresentando temperatura média anual de $16^{\circ} \mathrm{C}$, sendo o mês mais quente com $20^{\circ} \mathrm{C}$ eo mais frio com $13^{\circ} \mathrm{C}$, e precipitação anual média de $1500 \mathrm{~mm}$.
O experimento teve a duração de oito meses (entre junho de 2008 e fevereiro de 2009), sendo que as mudas ficaram quatro meses em casa de vegetação e quatro meses em área de rustificação.

Foram testados três tipos de substratos: substrato comercial à base de casca de Pinus compostada e vermiculita e substratos à base de resíduos de podas de árvores trituradas compostadas com lodo de esgoto aeróbio nas proporções 3:1 (v:v) e 2:1 (v:v).

O lodo de esgoto usado para os substratos foi coletado e compostado na estação de tratamento de esgoto ETE Belém, pertencente à SANEPAR, na cidade de Curitiba. Os resíduos de podas de árvores trituradas foram obtidos da arborização urbana de Curitiba. As misturas das proporções (3:1 e 2:1) foram realizadas em betoneiras e dispostas em leiras estáticas aeradas de aproximadamente 1,1 $\mathrm{m}$ de altura, 2,2 $\mathrm{m}$ de base e $4 \mathrm{~m}$ de comprimento. Após quatro meses, os compostos já estavam prontos para a utilização. Para a padronização do experimento, os compostos à base de lodo foram peneirados em malha de 2 $\mathrm{mm}$, visando à obtenção de granulometria similar à apresentada pelo substrato comercial.

As análises de teores totais de metais pesados foram realizadas no Laboratório de Pesquisas Hidrogeológicas da Universidade Federal do Paraná - UFPR, segundo a metodologia da American Public Health Association - APHA (1998). Os parâmetros parasitológicos (ovos de helmintos) foram obtidos no Laboratório de Parasitologia Molecular UFPR, segundo metodologia descrita por Soccol et al. (2000). Tais resultados demonstraram que os substratos higienizados por compostagem estavam aptos para o uso agrícola, atendendo às Resoluções do Conselho Nacional de Meio Ambiente - CONAMA no 375/2006 e Secretaria Estadual de Meio Ambiente do Paraná - SEMA-PR n ${ }^{\circ} 021 /$ 2009 (Tabelas 1 e 2).

Tabela 1 - Teores totais de metais pesados em amostra composta pelos dois compostos à base de lodo de esgoto e podas de árvores trituradas utilizados como substratos. Os números entre parênteses representam os limites estabelecidos pela Resolução CONAMA $\mathrm{n}^{\mathrm{o}} 375 / 2006$.

Table 1 - Total heavy metal concentrations in a sample composed by two composted substrates based on sewage sludge and crushed pruning trees. The numbers between parentheses represent the established limits proposed by CONAMA resolution ( $n^{\circ}$ $375 / 2006)$.

\begin{tabular}{ccccc}
\hline $\mathrm{Al}$ & $\mathrm{Cd}$ & $\mathrm{Pb}$ & $\mathrm{Na}$ & $\mathrm{Cr}$ \\
\hline & & $\%$ & & \\
\hline 0,86 & $<0,001(0,0039)$ & $<0,005(0,03)$ & $<0,01$ & $<0,005(0,1)$ \\
\hline
\end{tabular}

Cerne, Lavras, v. 18, n. 4, p. 613-621, out./dez. 2012 
Tabela 2 - Parâmetros parasitológicos (ovos viáveis por grama de sólidos totais) dos compostos a base de lodo de esgoto e de podas de árvores trituradas utilizados como substratos.

Table 2 - Parasitological parameters (viable eggs per gram of total solids) of the composted substrates based on sewage sludge and crushed pruning trees.

\begin{tabular}{lcc}
\hline \multirow{2}{*}{ Helminto } & \multicolumn{2}{c}{ Composto } \\
\cline { 2 - 3 } & $3: 1$ & $2: 1$ \\
\hline Ascaris sp. & 0 & 0,05 \\
Toxocara sp. & 0 & 0,01 \\
Trichuris trichiura & 0 & 0,00 \\
Trichuris vulpis & 0 & 0,01 \\
Trichuroidea & 0 & 0,01 \\
Hymenolepis diminuta & 0 & 0,01 \\
Taenia sp. & 0 & 0,00 \\
\hline Total Geral & 0 & 0,10 \\
\hline Protozoários & 0,28 & 0,38 \\
\hline
\end{tabular}

Nota: análises realizadas em triplicatas

Limite estabelecido pela Resolução CONAMA n 375/2006: ovos viáveis de helmintos $<0,25$ ovo por grama de sólidos totais (CONSELHO NACIONAL DO MEIO AMBIENTE CONAMA, 2006)

Três doses de fertilizante foram testadas em cada substrato: testemunha (sem fertilizante); dose padrão $2,7 \mathrm{~g}$ de fertilizante granulado $\left(\mathrm{N} ; \mathrm{P}_{2} \mathrm{O}_{5} ; \mathrm{K}_{2} \mathrm{O}-15-9-12\right)$ de liberação lenta (5-6 meses) por $\mathrm{dm}^{3}$; e dose alta - $4 \mathrm{~g}$ de fertilizante por $\mathrm{dm}^{3}$, havendo nove tratamentos no total, com quatro repetições, cada uma constituída de pelo menos 10 plantas úteis. O padrão de fertilização usado em viveiros da SANEPAR é a dose de $2,7 \mathrm{~g} . \mathrm{dm}^{-3} \mathrm{do}$ mesmo fertilizante usado nesse experimento, sendo este adicionado ao substrato comercial de casca de Pinus compostada e vermiculita, para a produção de mudas usadas pela empresa.

A utilização da dose de $4 \mathrm{~g} \cdot \mathrm{dm}^{-3}$ foi escolhida para verificar se maiores níveis de fertilizante resultam em maior crescimento de mudas. Por meio de análises feitas no Laboratório de Nutrição de Plantas - UFPR, segundo Martins e Reissmann (2007), obtiveram-se os teores totais de macro e micronutrientes para cada substrato nos três diferentes níveis de fertilização (Tabela 3), bem como os teores de bases disponíveis no substrato comercial comumente utilizados nos viveiros da Sanepar (Tabela 4).

As sementes de Anadenanthera colubrina foram coletadas na região metropolitana de Curitiba e doadas pelo Instituto Ambiental do Paraná - IAP. A semeadura foi realizada manualmente colocando-se duas sementes a 0,5 $\mathrm{cm}$ de profundidade direto em tubetes plásticos de formato cônico e capacidade de $110 \mathrm{~cm}^{3}$ encaixados em bandejas. A irrigação foi realizada por meio de microaspersores, no início da manhã e final da tarde, tanto na casa de vegetação quanto na área de rustificação.

Nos tubetes, onde mais de uma semente germinou, foi realizado o raleamento que consiste no corte da muda menos desenvolvida. Ao atingirem oito meses de idade, pelo menos 10 mudas úteis de cada repetição (descartandose as plantas das bordaduras) foram mensuradas para a

Tabela 3 - Teores totais de macro e micronutrientes nos substratos testados (03/2008).

Table 3 - Total macro and micronutrient concentrations in the tested substrates.

\begin{tabular}{|c|c|c|c|c|c|c|c|c|c|}
\hline Tratamentos & $\mathrm{N}$ & $\mathrm{P}$ & $\mathrm{K}$ & $\mathrm{Ca}$ & $\mathrm{Mg}$ & $\mathrm{Fe}$ & $\mathrm{Mn}$ & $\mathrm{Cu}$ & $\mathrm{Zn}$ \\
\hline $\begin{array}{l}\text { Substrato / dose de } \\
\text { fertilizante em g.dm }\end{array}$ & & $\left(\mathrm{g} \cdot \mathrm{kg}^{-1}\right)$ & & & & & g. $\left.\mathrm{kg}^{-1}\right)$ & & \\
\hline Comercial / 0 & 5,8 & 2,6 & 2,1 & 12,9 & 9,23 & 5780 & 78 & 12 & 9 \\
\hline Comercial / 2,7 & 5,0 & 2,2 & 2,8 & 11,5 & 9,86 & 7475 & 117 & 18 & 13 \\
\hline Comercial / 4,0 & 5,7 & 2,5 & 3,5 & 6,5 & 5,63 & 6266 & 105 & 27 & 16 \\
\hline Composto $3: 1 / 0$ & 19,6 & 8,0 & 2,7 & 17,1 & 4,49 & 10793 & 371 & 66 & 103 \\
\hline Composto $3: 1 / 2,7$ & 20,6 & 8,2 & 4,9 & 19,4 & 5,27 & 9233 & 378 & 72 & 100 \\
\hline Composto $3: 1 / 4,0$ & 20,9 & 8,3 & 6,2 & 18,2 & 4,98 & 8887 & 367 & 86 & 105 \\
\hline Composto 2:1 / 0 & 19,3 & 8,4 & 2,9 & 16,0 & 4,17 & 10388 & 395 & 73 & 117 \\
\hline Composto 2:1 / 2,7 & 20,1 & 8,5 & 4,6 & 16,8 & 4,40 & 9873 & 406 & 86 & 117 \\
\hline Composto 2:1 / 4,0 & 22,0 & 8,3 & 5,4 & 16,0 & 4,47 & 10456 & 385 & 38 & 118 \\
\hline
\end{tabular}


Tabela 4 - Propriedades químicas do substrato comercial com fertilização mineral comumente utilizado nos viveiros da Sanepar.

Table 4 - Chemical properties of commercial substrate with mineral fertilizer commonly used at Sanepar forest nurseries.

\begin{tabular}{|c|c|c|c|c|c|c|c|c|c|c|c|c|c|c|}
\hline Amostra & \multicolumn{2}{|c|}{$\mathrm{pH}$} & $\mathrm{Al}^{+3}$ & $\mathrm{H}^{+}+\mathrm{Al}^{+3}$ & $\mathrm{Ca}^{+2}$ & $\mathrm{Mg}^{+2}$ & $\mathrm{~K}^{+}$ & SB & $\mathrm{T}$ & $\mathrm{P}$ & $\mathrm{C}$ & V & $\mathrm{m}$ & $\mathrm{Ca} / \mathrm{Mg}$ \\
\hline \multirow{2}{*}{$\begin{array}{c}\text { Comercial } \\
/ 2,7\end{array}$} & $\mathrm{CaCl}_{2}$ & SMP & \multicolumn{7}{|c|}{$\mathrm{cmol}_{\mathrm{c}} \mathrm{dm}^{-3}$} & $\mathrm{mg} \mathrm{dm} \mathrm{m}^{-3}$ & $\mathrm{~g} \mathrm{dm}^{-3}$ & $\%$ & $\%$ & \\
\hline & 5,9 & 6,2 & 0 & 4,2 & 18,3 & 5,1 & 1,2 & 24,6 & 28,8 & 721,8 & 133,8 & 85 & 0 & 3,6 \\
\hline
\end{tabular}

obtenção das alturas, diâmetros de coleto e massas secas das partes aéreas (folhas e ramos). A altura foi medida com régua graduada e o diâmetro com um paquímetro digital $(0,01 \mathrm{~mm})$. Para a obtenção dos dados de massa seca, foram cortadas, na base do caule, três plantas por repetição e, em seguida, dispostas em embalagens de papel submetidas à secagem em estufa a $60^{\circ} \mathrm{C}$ por 72 horas. O material vegetal seco foi separado em folhas e ramos, e estes foram pesados em balança analítica (precisão 0,001 g) e, em seguida, descartados.

$\mathrm{O}$ experimento foi conduzido em delineamento inteiramente casualizado em arranjo fatorial $3 \times 3$ (três tipos de substrato $x$ três doses de fertilizante). Para a verificação da homogeneidade das variâncias e outras condicionantes, foram realizados testes de Bartlett. Após a análise do efeito da interação entre os fatores (interações entre os fatores detectadas para todas as características morfológicas analisadas), análises de variância e testes de Tukey (5\% de probabilidade) foram realizados para a comparação das médias. Os efeitos das doses de fertilizante (fator quantitativo) também foram avaliados por regressões polinomiais.

\section{RESULTADOS E DISCUSSÃO}

Para a altura, a dose intermediária de fertilizante $\left(2,7\right.$ g.dm $\left.{ }^{-3}\right)$ foi suficiente para a obtenção dos maiores valores nos substratos comercial e à base de lodo 3:1, não diferindo da dose alta $\left(4 \mathrm{~g} . \mathrm{dm}^{-3}\right)$. Para o substrato $2: 1$, a dose de 0 g.dm ${ }^{-3}$ não diferiu estatisticamente, pelo teste de Tukey $(\mathrm{p}<0,05)$, das demais doses para essa característica morfológica (Tabela 5), indicando, provavelmente, boas condições físicas e nutricionais deste substrato de lodo compostado. Nos tratamentos sem a adição de fertilizante, apenas o substrato comercial apresentou média menor para a altura, corroborando para a indicação de que os compostos à base de lodo possuem consideráveis quantidades de nutrientes (ALTAFIN et al., 2004; FAUSTINO et al., 2005; GUEDES; POGGIANI, 2003; MORAIS et al., 1997; SCHEER et al., 2010, 2011), propiciando bom crescimento (Tabela 3). As regressões apresentadas nas Figuras 1 e 2 reforçam os resultados de que doses maiores que $2,7 \mathrm{~g} . \mathrm{dm}^{-3}$ não necessariamente resultam em aumentos consistentes para alturas e diâmetros das mudas de monjoleiro.

No substrato 3:1, os maiores diâmetros de coleto responderam ao aumento das doses de fertilizante, enquanto que para o substrato 2:1 e o comercial, o nível intermediário foi suficiente para a obtenção dos maiores diâmetros (Tabela 5). Sem fertilização, o diâmetro apresentou aumento significativo com o uso do lodo de esgoto. Essa característica morfológica, em geral, é a mais observada para avaliar a capacidade de sobrevivência de uma muda em campo, bem como pode definir as doses de fertilizantes a serem aplicadas (CARNEIRO, 1995).

As relações altura/diâmetro (entre 8,9 e 11,7) obtidas com base nos dados da Tabela 5 indicam valores um pouco acima dos limites de 5,4 a 8,1, sugeridos por Carneiro (1995). No entanto, cada espécie pode apresentar características diferentes nos diversos estágios de desenvolvimento das mudas, e depende, também, dos tipos de sistemas de produção utilizados (tubetes, sacos, vasos, etc). Os valores obtidos no presente estudo são similares aos observados por Scheer et al. (2011), na produção de mudas de Calophyllum brasiliense (guanandi) em compostos de lodo de esgoto também utilizando tubetes de $110 \mathrm{~cm}^{3}$.

Com o aumento das doses de fertilizante, a massa seca foliar apresentou a tendência de maiores valores, apesar do teste de Tukey não apontar diferenças significativas $(\mathrm{p}<0,05)$ entre as doses de 2,7 e 4 g.dm ${ }^{-3}$ com o substrato comercial e com o composto 2:1 (Tabela $6)$. As maiores médias para a massa seca foliar de ambos os compostos à base de lodo indicam a superioridade nutricional, sem uso de fertilizante, em relação ao substrato comercial. O nível de fertilização de $2,7 \mathrm{~g}$. $\mathrm{dm}^{-3}$ foi suficiente para igualar as médias entre os substratos, enquanto que, com $4 \mathrm{~g} . \mathrm{dm}^{-3}$ de fertilizante, os resultados para o composto $3: 1$ foram ainda maiores que com $2,7 \mathrm{~g} \cdot \mathrm{dm}^{-3}$ de fertilização (Tabela 6).

Cerne, Lavras, v. 18, n. 4, p. 613-621, out./dez. 2012 
Tabela 5 - Médias de altura e diâmetro de coleto de Anadenanthera colubrina aos oito meses após germinação, nos três tipos de substratos e fertilizantes; $n=4$.

Table 5 - Anadenanthera colubrina heights and diameters at eight months after germination in three substrate types and fertilizer levels; $n=4$

\begin{tabular}{|c|c|c|c|c|c|c|c|c|c|c|c|}
\hline \multirow[b]{3}{*}{ Substrato } & \multicolumn{5}{|c|}{ Altura (cm) } & \multicolumn{6}{|c|}{ Diâmetro de coleto (mm) } \\
\hline & \multicolumn{11}{|c|}{ Fertilizante $\left(\mathrm{g} \mathrm{dm}^{-3}\right)$} \\
\hline & 0 & & 2,7 & 4 & & 0 & & 2,7 & & 4 & \\
\hline Comercial & $26,1 \pm 2,0$ & $\mathrm{bB}$ & $48,0 \pm 1,9$ aA & $47,9 \pm 3,3$ & $\mathrm{aA}$ & $2,3 \pm 0,1$ & $\mathrm{cB}$ & $4,8 \pm 0,1$ & $\mathrm{aA}$ & $4,9 \pm 0,2$ & $\mathrm{bA}$ \\
\hline Composto $3: 1$ & $36,8 \pm 1,4$ & $\mathrm{aB}$ & $46,9 \pm 1,7 \quad \mathrm{aA}$ & $48,2 \pm 3,4$ & $\mathrm{aA}$ & $4,0 \pm 0,1$ & $\mathrm{bC}$ & $4,9 \pm 0,1$ & $\mathrm{aB}$ & $5,3 \pm 0,1$ & $\mathrm{aA}$ \\
\hline Composto $2: 1$ & $42,5 \pm 1,9$ & $\mathrm{aA}$ & $43,5 \pm 0,9 \quad \mathrm{aA}$ & $46,7 \pm 1,7$ & $\mathrm{aA}$ & $4,7 \pm 0,1$ & $\mathrm{aB}$ & $5,1 \pm 0,1$ & $\mathrm{aA}$ & $5,2 \pm 0,1$ & $\mathrm{abA}$ \\
\hline
\end{tabular}

As médias seguidas da mesma letra maiúscula na linha e da mesma letra minúscula na coluna não diferem entre si, estatisticamente, pelo teste de Tukey a $5 \%$ de probabilidade.

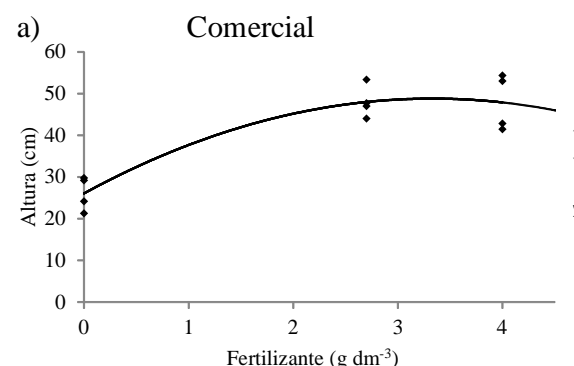

$\hat{\mathrm{y}}=26,07+13,65 \mathrm{x}-0,205 \mathrm{x}^{2}$

$$
\mathrm{R}^{2}=0,847^{*}
$$

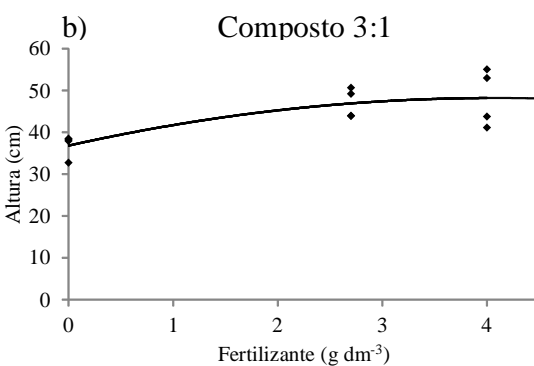

$\hat{\mathrm{y}}=26,8+5,587 \mathrm{x}-0,685 \mathrm{x}^{2}$

$\mathrm{R}^{2}=0,61 *$

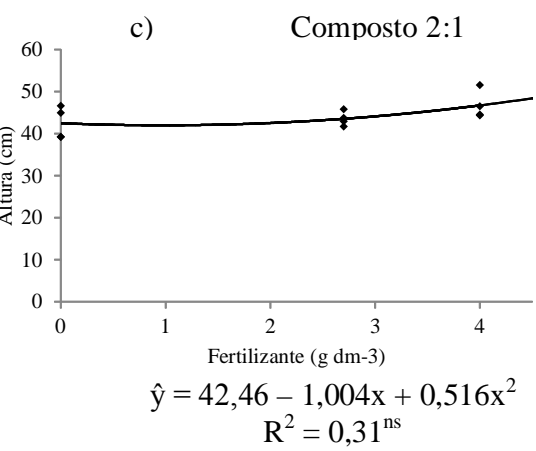

$*=$ significativo a $5 \%$ de probabilidade; ${ }^{\text {ns }}=$ não significativo a $5 \%$ de probabilidade

Figura 1 - Regressões polinomiais para altura de mudas de Anadenanthera colubrina nos três tipos de substratos em função dos níveis de fertilização.

Figure 1 - Polynomial regressions for Anadenanthera colubrina heights at eight months after germination in three substrate types and fertilizer levels.
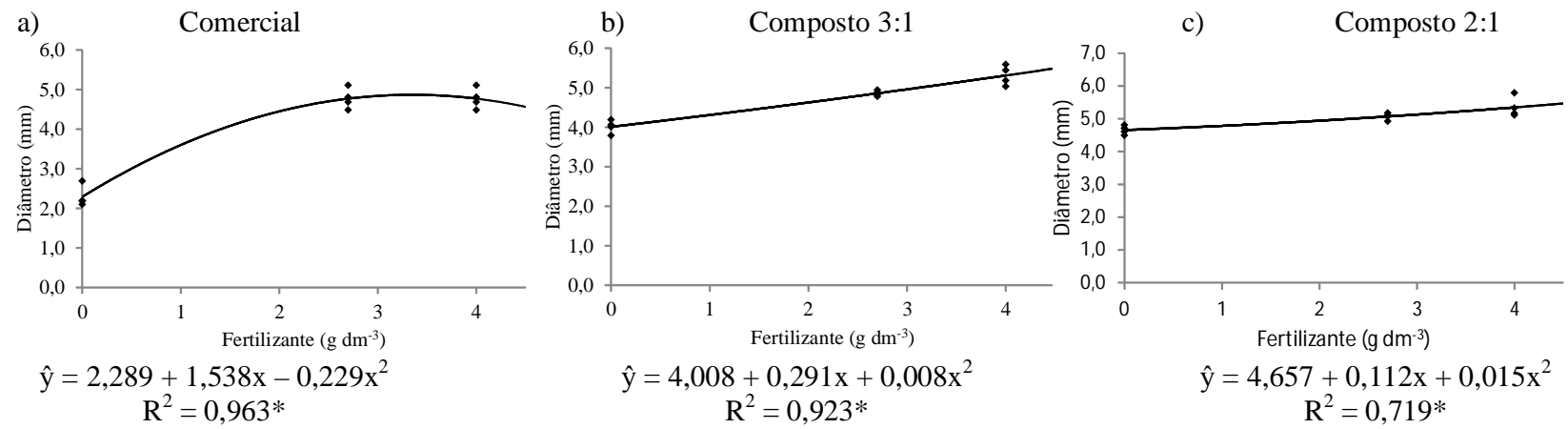

$*$ = significativo a $5 \%$ de probabilidade.

Figura 2 - Regressões polinomiais para diâmetro de coleto de mudas de Anadenanthera colubrina nos três tipos de substratos em função dos níveis de fertilização.

Figure 2 - Polynomial regressions for Anadenanthera colubrina diameters at eight months after germination in three substrate types and fertilizer levels.

Cerne, Lavras, v. 18, n. 4, p. 613-621, out./dez. 2012 
Tabela 6 - Médias de massa seca de folhas e ramos Anadenanthera colubrina aos oito meses após germinação, nos três tipos de substratos e fertilizantes testados; $\mathrm{n}=4$.

Table 6 - Dry mass of Anadenanthera colubrina leaves and branches at eight months after germination in three substrate types and fertilizer levels; $n=4$.

\begin{tabular}{|c|c|c|c|c|c|c|c|c|c|c|c|}
\hline \multirow{4}{*}{$\begin{array}{l}\text { Substrato } \\
\text { Comercial }\end{array}$} & \multicolumn{5}{|c|}{ Folhas (g) } & \multicolumn{6}{|c|}{ Ramos (g) } \\
\hline & \multicolumn{11}{|c|}{ Fertilizante $\left(\mathrm{g} \mathrm{dm}^{-3}\right)$} \\
\hline & 0 & \multicolumn{2}{|c|}{2,7} & \multicolumn{2}{|l|}{4} & \multicolumn{2}{|c|}{0} & \multicolumn{2}{|c|}{2,7} & \multicolumn{2}{|c|}{4} \\
\hline & $0,2 \pm 0,1 \mathrm{bB}$ & $1,1 \pm 0,1$ & $\mathrm{aA}$ & $1,2 \pm 0,2$ & $\mathrm{aA}$ & $0,2 \pm 0,1$ & $\mathrm{bB}$ & $1,1 \pm 0,1$ & $\mathrm{aA}$ & $1,3 \pm 0,2$ & $\mathrm{aA}$ \\
\hline Composto $3: 1$ & $0,6 \pm 0,1 \mathrm{aC}$ & $0,9 \pm 0,1$ & $\mathrm{aB}$ & $1,3 \pm 0,1$ & $\mathrm{aA}$ & $0,6 \pm 0,1$ & $a b B$ & $0,8 \pm 0,1$ & $\mathrm{aAB}$ & $1,2 \pm 0,1$ & $\mathrm{aA}$ \\
\hline Composto $2: 1$ & $0,9 \pm 0,1 \mathrm{aB}$ & $1,1 \pm 0,1$ & $\mathrm{aAB}$ & $1,3 \pm 0,1$ & $\mathrm{aA}$ & $0,8 \pm 0,1$ & $\mathrm{aB}$ & $0,9 \pm 0,1$ & $\mathrm{aAB}$ & $1,3 \pm 0,1$ & $\mathrm{aA}$ \\
\hline
\end{tabular}

As médias seguidas da mesma letra maiúscula na linha e da mesma letra minúscula na coluna não diferem entre si, estatisticamente, pelo teste de Tukey a $5 \%$ de probabilidade.

Constatou-se, também, uma tendência de aumento da massa seca de ramos com maiores doses de fertilizante. Para os compostos com lodo, as diferenças foram significativas entre as doses 0 e 4 g. $\mathrm{dm}^{-3}$ de fertilizante, apresentando ainda umacerta diferenciação entre os valores de 2,7 e 4 g.dm ${ }^{-3}$ (porém não diferente estatisticamente pelos testes de Tukey), enquanto que para o composto comercial a dose de $2,7 \mathrm{~g} . \mathrm{dm}^{-3}$ foi estatisticamente similar à dose mais alta. Observa-se, ainda, que sem o uso de fertilizante, o composto 2:1 apresentou maior massa seca de ramos que o substrato comercial (Tabela 6).

Os compostos à base de lodo apresentaram mudas com maior massa seca total (folhas + ramos) se comparados ao substrato comercial, ambos sem adição de fertilizante, sendo a diferença das médias de quatro a cinco vezes maior nos compostos em relação ao substrato comercial (Tabela 7). Para o composto comercial foi observada uma grande diferença de valores médios entre $0 \mathrm{e} 2,7 \mathrm{~g} \cdot \mathrm{dm}^{-3} \mathrm{de}$ fertilização, o que não foi tão evidenciado para os compostos à base de lodo, indicando melhores níveis de fertilidade desses substratos (Tabela 7, Figura 3). Com a maior dose de fertilizante, o composto 3:1 foi o único a apresentar massa seca aérea total superior estatisticamente à dose de $2,7 \mathrm{~g}$.dm${ }^{3}$ (Tabela 7), embora pequenas diferenças tenham sido encontradas na análise de regressão (Figura 3).

Segundo McLachlan et al. (2004) e Wilson et al. (2006), compostos à base de lodo e podas de árvores apresentam teores elevados de N, P, K, Zn, Cu, Mn, Al e Fe. Isso pode ser claramente observado na Tabela 3, comparando-se com o substrato comercial. Os macronutrientes $\mathrm{N}, \mathrm{P}$ e K estão diretamente ligados ao desenvolvimento da planta, uma vez que $\mathrm{N}$ é um componente essencial para a constituição das proteínas e enzimas; P é crucial para o processo fotossintético, transformando energia luminosa em energia química; e K regula a perda de água, atuando na abertura e fechamento dos estômatos, além de participar da síntese de proteínas, carboidratos e relações osmóticas (MALAVOLTA, 2006), sendo a ausência ou pequena concentração desses elementos responsável pelo crescimento deficiente das plantas, conforme observado no substrato comercial sem adição de fertilizante.

Ao analisar o desempenho das mudas nos compostos de lodo $3: 1$ e 2:1, em relação às mudas no substrato comercial sem fertilizante, recomendado pelo fabricante apenas como substrato, necessitando, obrigatoriamente, fertilização, fica, obviamente, evidenciada a superioridade nutricional dos compostos com lodo (Tabela 3), o que contribui para a produção de mudas com boa qualidade (Tabelas 5, 6 e 7). Os valores obtidos para os mesmos compostos em comparação com o substrato comercial com a adição de doses de 2,7 e 4 g.dm ${ }^{-3}$ mostramse estatisticamente similares para quase todas as variáveis e tratamentos testados (Tabelas 5, 6 e 7).

Resultados indicando crescimentos similares ou melhores de mudas em substratos com lodo de esgoto em relação a substratos comerciais, também foram obtidos por Nóbrega et al. (2007), na produção de mudas de Schinus terebinthifolius, por Wilson et al. (2006) em mudas de Forestiera segregata var. pinerotum, Myrcianthes fragrans e Viburnum obovatum, por Maia (1999) para a produção de mudas de Pinus taeda, Scheer et al. (2010) para Parapiptadenia rigida e Scheer et al. (2012) para Prunus brasiliensis. Segundo esses autores e Ingelmo et al. (1998), o uso de lodos de esgoto como componentes de substratos para a produção de mudas também é uma alternativa economicamente viável aos substratos comerciais, dado a economia de insumos e qualidade das mudas, além do aspecto ambiental.

\section{Cerne, Lavras, v. 18, n. 4, p. 613-621, out./dez. 2012}


Tabela 7 - Médias de massa seca aérea total de Anadenanthera colubrina aos oito meses após germinação, nos três tipos de substratos e fertilizantes testados; $\mathrm{n}=4$.

Table 7 - Total aerial dry mass of Anadenanthera colubrina at eight months after germination in three substrate types and fertilizer levels; $n=4$.

\begin{tabular}{lccc}
\hline \multicolumn{4}{c}{ Massa seca da parte aérea total $(\mathrm{g})$} \\
\hline \multicolumn{4}{c}{ Fertilizante $\left(\mathrm{g} \mathrm{dm}^{-3}\right)$} \\
\hline Substrato & 0 & 2,7 & 4 \\
\hline Comercial & $0,3 \pm 0,1 \mathrm{bB}$ & $2,2 \pm 0,1 \mathrm{aA}$ & $2,5 \pm 0,4 \mathrm{aA}$ \\
Composto $3: 1$ & $1,1 \pm 0,2 \mathrm{aB}$ & $1,7 \pm 0,2 \mathrm{aB}$ & $2,5 \pm 0,1 \mathrm{aA}$ \\
Composto $2: 1$ & $1,7 \pm 0,1 \mathrm{aB}$ & $2,0 \pm 0,1 \mathrm{aAB}$ & $2,6 \pm 0,2 \mathrm{aA}$ \\
\hline
\end{tabular}

As médias seguidas da mesma letra maiúscula na linha e da mesma letra minúscula na coluna não diferem entre si, estatisticamente, pelo teste de Tukey a $5 \%$ de probabilidade.
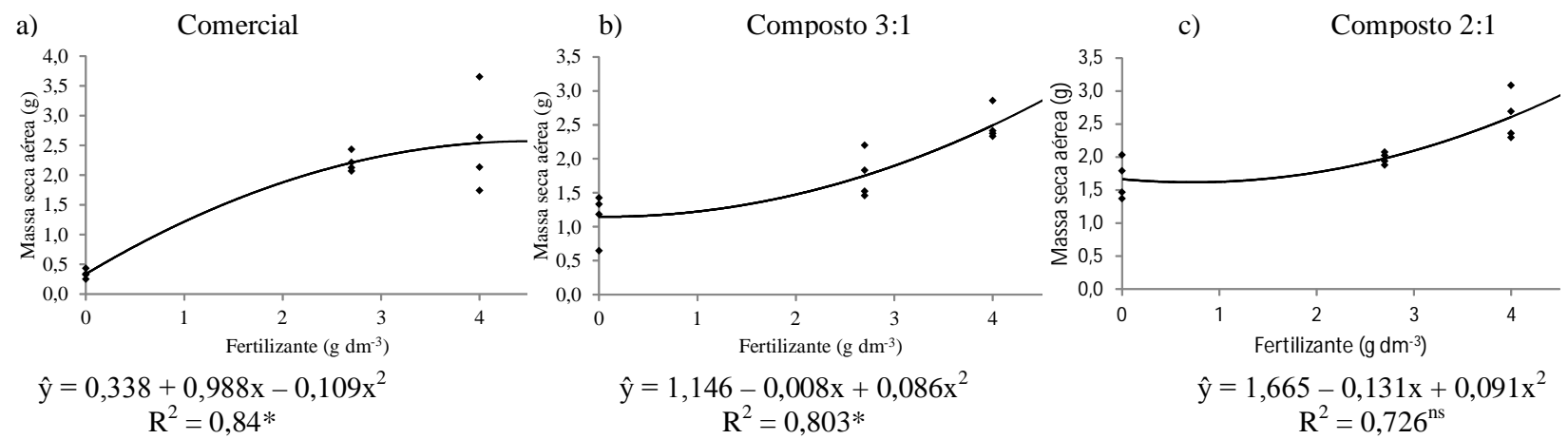

$*$ = significativo a $5 \%$ de probabilidade.

Figura 3 - Regressões polinomiais para massa seca aérea de mudas de Anadenanthera colubrina nos três tipos de substratos em função dos níveis de fertilização.

Figure 3 - Polynomial regressions for Anadenanthera colubrina aerial dry mass at eight months after germination in three substrate types and fertilizer levels.

\section{CONCLUSÕES}

A comparação dos dados obtidos para os três substratos indica que os compostos de poda de árvores triturados e lodo de esgoto possuem boas características físico-hídricas e nutricionais, permitindo bons resultados no crescimento (altura, diâmetro, massa seca de folhas e ramos) para mudas de Anadenanthera colubrina. Os nutrientes presentes nos substratos à base de lodo sem fertilização mineral já são suficientes para promover um bom crescimento das plantas, entretanto, estes apresentam ainda resposta positiva à fertilização adicional.

A adição da dose de $2,7 \mathrm{~g} \cdot \mathrm{dm}^{-3}$ de fertilizante de liberação lenta, tanto nos compostos à base de lodo quanto no substrato comercial, mostrou-se capaz de promover um crescimento adequado às mudas, obtendo resultados bastante próximos à adubação com $4 \mathrm{~g} \cdot \mathrm{dm}^{-3}$ para a maioria das variáveis testadas no experimento, mas com economia de fertilizante

Os resultados observados para os compostos à base de lodo comprovam que estes podem ser usados para substituir substratos comerciais, em razão da economia de insumos, da sustentabilidade e do adequado crescimento das mudas. Deve-se, no entanto, obedecer aos aspectos legais para a utilização de lodo de esgoto, que regulam sobre teores de metais pesados e parâmetros sanitários (higienização ou esterilização).

\section{AGRADECIMENTOS}

À Companhia de Saneamento do Paraná (SANEPAR) pelo apoio a essa pesquisa, em especial ao Cleverson Andreoli e Maria Arlete Rosa. Somos gratos ao auxílio de campo de Laercio Chemim, Márcia de Lima, Gessuelyton de Lima, Juliana Wojciechowski e a empresa Reciclom.

Cerne, Lavras, v. 18, n. 4, p. 613-621, out./dez. 2012 


\section{REFERÊNCIAS}

ALTAFIN, V. L.; POLONIO, W.; MEDEIROS, G. A.; BRANDÃO, M. F.; ZUIN, F. D.; BUSCARATO, E. A.; MENEZES, M. O. Utilização de lodo de fosfatização na produção de mudas de espécies nativas. Engenharia Ambiental, Espírito Santo do Pinhal, v. 1, n. 1, p. 45-50, 2004.

AMERICAN PUBLIC HEALTH ASSOCIATION. Standard methods for the examination of water and wastewater. $20^{\text {th }}$ ed. Washington, 1998.

CARNEIRO, J. G. A. Produção e controle de qualidade de mudas florestais. Curitiba: UFPR/FUPEF, 1995.

CARVALHO, P. E. R. Espécies florestais brasileiras: recomendações silviculturais, potencialidades e usos da madeira. Colombo: EMBRAPA-CNPF/SPI, 1994. 640 p.

CONSELHO NACIONAL DO MEIO AMBIENTE.

Resolução No $\mathbf{3 7 5}$, de 29 de agosto de 2006. Define critérios e procedimentos, para o uso agrícola de lodos de esgoto gerados em estações de tratamento de esgoto sanitário e seus produtos derivados. Brasília: Ministério do Meio Ambiente, 2006. Disponível em: <http://www.mma.gov.br/port/conama/ res/res06/res37506.pdf>. Acesso em: 10 nov. 2011.

FAUSTINO, R.; KATO, M. T.; FLORÊNCIO, L.; GAVAZZA, S. Lodo de esgoto como substrato para produção de mudas de Senna siamea Lam. Revista Brasileira de Engenharia Agrícola e Ambiental, Campina Grande, v. 9, p. 278-282, 2005.

FERRETTI, A. R.; KAGEYAMA, P. Y.; ÁRBOCZ, G. F.; SANTOS, J. D.; BARROS, M. I. A.; LORZA, R. F.;

OLIVEIRA, C. Classificação das espécies arbóreas em grupos ecológicos para revegetação com nativas no Estado de São Paulo. Florestar Estatístico, São Paulo, v. 3, n. 7, p. 73-84, 1995.

GUEDES, M. C.; POGGIANI, F. Variação dos teores de nutrientes foliares em eucalipto fertilizado com biossólido. Scientia Florestalis, Piracicaba, n. 63, p. 188-201, 2003.

GUERRINI, I. A.; TRIGUEIRO, R. M. Atributos físicos e químicos de substratos compostos por biossólido e casca de arroz carbonizada. Revista Brasileira de Ciência do Solo, Viçosa, v. 28, n. 6, p. 1069-076, nov./dez. 2004.
INGELMO, F; CANET, R.; IBANEZ, M. A.; POMARES, F; GARCIA, J. Use of MSW compost, dried sewage sludge and other wastes as partial substitutes for peat and soil. Bioresource Technology, Essex, v. 63, n. 2, p. 123-129, 1998.

MAIA, C. M. B. F. Uso de casca de Pinus e lodo biológico como substrato para a produção de mudas de Pinus taeda. Boletim de Pesquisa Florestal, Colombo, n. 39, p. 81-82, 1999.

MALAVOLTA, E. Manual de nutrição mineral de plantas. São Paulo: Agronômica Ceres, 2006. 638 p.

MARTINS, A. P. L.; REISSMANN, C. B. Material vegetal e as rotinas laboratoriais nos procedimentos químico-analíticos. Scientia Agraria, Piracicaba, v. 8, n. 1, p. 1-17, 2007.

MCLACHLAN, K. L.; CHONG, C.; VORONEY, R. P.; LIU, H. W.; HOLBEIN, B. E. Variability of soluble salts using different extraction methods on composts and other substrates. Compost Science \& Utilization, Emmaus, v. 12, p. $180-184,2004$

MORAIS, S. M. de J.; ATAIDES, P. R. V.; GARCIA, D. C.; KURTZ, F. C.; OLIVEIRA, O. S.; WATZLAWICK, L. F. Uso do lodo de esgoto da Corsan, Santa Maria (RS), comparada com outros substratos orgânicos Sanare, Curitiba, v. 6, n. 6, p. 44-49, 1997.

NASCIMENTO, C. W. A.; BARROS, D. A. S.; MELLO, E. E. C.; OLIVEIRA, A. B. Alterações químicas em solos e crescimento de milho e feijoeiro após a aplicação de lodo de esgoto. Revista Brasileira de Ciência do Solo, Viçosa, v. 28, n. 2, p. 385-392, mar./abr. 2004.

NÓBREGA, R. S. A.; BOAS, R. C. V.; NOBREGA, J. C. A.; PAULA, A. M.; MOREIRA, F. M. S. Utilização de biossólido no crescimento inicial de mudas de aroeira (Schinus terebinthifolius Raddi). Revista Árvore, Viçosa, v. 31, n. 2, p. 239-246, mar./abr. 2007.

PEGORINI, E. S. Avaliação de impactos ambientais do programa de reciclagem agrícola de lodo de esgoto na região metropolitana de Curitiba. 2002. 107 p. Dissertação (Mestrado em Agronomia) - Universidade Federal do Paraná, Curitiba, 2002.

ROCHA, G. N.; GOLÇALVES, J. L. M.; MOURA, I. M. Mudanças da fertilidade do solo e crescimento de um povoamento de Eucalyptus grandis fertilizado com biossólido. Revista Brasileira de Ciência do Solo, Viçosa, v. 28, n. 4, p. 623-639, 2004. 
ROCHA, M. T.; SHIROTA, R. Disposição final de lodo de esgoto. Revista de Estudos Ambientais, Blumenau, v. 1, n. 3, p. 1-25, 1999.

SCHEER, M. B.; CARNEIRO, C.; SANTOS, K. G. Crescimento de mudas de Prunus brasiliensis (Cham. \& Schltdl.) D. Dietr. em substratos à base de lodo de esgoto compostado e fertilizante mineral. Revista Ciência Florestal, Santa Maria, 2012. No prelo.

SCHEER, M. B.; CARNEIRO, C.; SANTOS, K. G. Substratos à base de lodo de esgoto compostado na produção de mudas de Paraptadenia rigida (Benth.) Brenan. Scientia Forestalis, Piracicaba, v. 38, n. 88, p. 637-644, 2010.

SCHEER, M. B.; CARNEIRO, C.; SANTOS, K. G.; BRESSAN, O. A.; HOROKOSKI, G. Produção de mudas de Calophyllum brasiliense Cambess com substratos comercial e à base de lodo de esgoto compostado. Revista DAE, São Paulo, v. 185 , p. 55-61, 2011.

SILVA, J. E.; RESCK, D. V. S.; SHARMA, R. D. Alternativa agronômica para o biossólido produzido no Distrito Federal: II., aspectos qualitativos, econômicos e práticos de seu uso. Revista Brasileira de Ciência do Solo, Viçosa, v. 26, n. 2, p. 497-503, mar./abr. 2002.

SOCCOL, V. T.; PAULINO, R. C.; CASTRO, E. A. Metodologia de análise parasitológica em lodo de esgoto e esgoto. In: ANDREOLI, C. V.; BONNET, B. R. P. (Ed.). Manual de métodos para análises microbiológicas e parasitológicas em reciclagem agrícola de lodo de esgoto. Curitiba: SANEPAR, 2000. p. 27-41.

WILSON, S. B.; MECCA, L. K.; DANIELSON, H. E.; GRAETZ, D. A.; STOFFELA, P. J. Container and field evaluation of three native shrubs grown in compost-based media. Compost Science $\&$ Utilization, Emmaus, v. 14, n. 3, p. 178-183, 2006. 